\title{
Efficacy of Renal Preservation: Comparative Study of Celsior and University of Wisconsin Solutions
}

\author{
P. Nunes, A. Mota, A. Figueiredo, F. Macário, F. Rolo, V. Dias, and B. Parada
}

\begin{abstract}
Objective. We sought to compare the efficacy of Celsior and University of Wisconsin (UW) solutions on the perfusion and cold storage of renal grafts for human transplantation.

Patients and Methods. Retrospective analyses of 313 kidney transplants were performed between 2002 and 2005; group A $(n=160)$, UW solution and group B $(n=153)$, Celsior solution were used in the preservation of the organs. The mean donor age was lower in group $\mathrm{B}$ (group $\mathrm{A}=42.67$ years vs group $\mathrm{B}=38.96$ years; $P<.05$ ), living donors were more frequent in the UW group (group $\mathrm{A}=10 \%$ vs group $\mathrm{B}=0.9 \% ; P<.001$ ). Multiorgan procurement procedures were more common in the Celsior group (group $\mathrm{A}=$ $75 \%$ vs group $\mathrm{B}=81.7 \% ; P<.001)$. Recipients with no associated comorbidities were more frequent in the UW group (group $\mathrm{A}=50 \%$ vs group $\mathrm{B}=36 \% ; P<.001$ ). Recipient mean age, cold ischemia time, and HLA matches were comparable.

Results. Delayed graft function (group $\mathrm{A}=22.7 \%$ vs group $\mathrm{B}=20.6 \%$ ), acute rejections (group $\mathrm{A}=21.4 \%$ vs group $\mathrm{B}=18.4 \%$ ), and serum creatinine at 6 months (group $\mathrm{A}=$ 1.75 vs group $B=1.67 \mathrm{mg} / \mathrm{dL}$ ), 1 year (group $A=1.47$ vs group $B=1.74 \mathrm{mg} / \mathrm{dL}$ ), and 2 years (group $\mathrm{A}=1.43$ vs group $\mathrm{B}=1.58 \mathrm{mg} / \mathrm{dL}$ ) showed no differences $(P=\mathrm{NS})$. Graft (group $\mathrm{A}=82.23 \%$ vs group $\mathrm{B}=84.11 \%$ ) and patient (group $\mathrm{A}=93 \%$ vs group $\mathrm{B}=$ $93.69 \%)$ survivals at 3 years were similar $(P=\mathrm{NS})$. There were no differences in the causes of graft loss.
\end{abstract}

Conclusion. The efficacy of UW and Celsior solutions is equivalent in the cold storage and renal preservation for transplantation.

$\mathrm{U}$ NIVERSITY OF WISCONSIN (UW) solution has a proven efficacy and is the "gold standard" for intraabdominal organ preservation, including kidney. ${ }^{1}$ Celsior, originally developed as a preservation solution for lung and heart, has also been proposed for liver and kidney. ${ }^{2}$ In this retrospective study our objective was to compare the safety and efficacy of both solutions in kidney preservation.

\section{PATIENTS AND METHODS}

Our unit performed 313 kidney transplantations between June 2002 and December 2005. We divided these transplants into 2 groups according to the solution used for cold storage and preservation of the grafts: group A $(n=160)$ with ViaSpan (Belzer UW) and group B $(\mathrm{n}=153)$ with Celsior (SangStat-Genzyme). Organs from cadaveric donors were flushed in situ through the aorta and on the bench after being harvested until a clear effluent was obtained. The perfusion of grafts from living donors was done on the bench. Organs were cold stored in a container of appropriate size on ice slush $\left(4^{\circ} \mathrm{C}\right)$ in a bath of the respective solution until grafted. Each group was calculated for the main factors related to the donor, graft, and recipient in terms of outcome measures for comparisons.

The statistical analysis was performed using commercial SPSS for Windows 10.0. Categorical metrics were compared by chisquare testing, and continuous variables by Student $t$ test, with Yates's correction or Fisher exact test wherever appropriate. Graft and patient cumulative actuarial survivals and survival curves were calculated by Kaplan-Meier analysis and tested for differences with the Mantel-Cox log-rank test. $P<.05$ was considered significant in every test for differences. Mean donor age was 42.67 years for the

From the Department of Urology and Renal Transplantation, Hospitais da Universidade de Coimbra, Coimbra, Portugal.

Address reprint requests to Pedro Nunes, Department of Urology and Renal Transplantation, Hospitais da Universidade de Coimbra, 3000 Coimbra, Portugal. E-mail: ptnunes@gmail.com

(c) 2007 by Elsevier Inc. All rights reserved. 360 Park Avenue South, New York, NY 10010-1710 
UW group and 38.96 years for the Celsior group $(P<.05)$; living donors also differed between groups (group $\mathrm{A}=10 \%$ vs group $\mathrm{B}=0.9 \% ; P<.001)$. Percentage of traumatic causes in cadaveric donors was similar (group $\mathrm{A}=61.6 \%$ vs group $\mathrm{B}=$ $65.3 \% ; P=\mathrm{NS}$ ), and local (our hospital) origin of these donors was also identical (group $\mathrm{A}=72.8 \%$ vs group $\mathrm{B}=87.5 \% ; P=$ NS). Multiorgan procurement (liver, heart, pancreas, or small bowel) was more frequent in the Celsior group (group A $=75 \%$ vs group $\mathrm{B}=81.7 \% ; P<.001)$. Donor creatinine (group $\mathrm{A}=$ 0.97 vs group $B=1.01 \mathrm{mg} / \mathrm{dL}$ ), recipient mean age (group $\mathrm{A}=$ 42.39 vs group $B=44.88$ years), mean time on dialysis pretransplantation (group $\mathrm{A}=35.44$ vs group $\mathrm{B}=38.88$ months), HLA average matches (group $\mathrm{A}=2.71$ vs group $\mathrm{B}=2.74$ ), and mean cold ischemia time (group $\mathrm{A}=18.17$ vs group $\mathrm{B}=18.75$ hours) were not statistically different between both groups $(P=\mathrm{NS})$. Recipients with no associated pathologies were more frequent in the UW group (group $\mathrm{A}=50 \%$ vs group $\mathrm{B}=36 \% ; P<.001$ ).

\section{RESULTS}

Mean follow-up was 2.24 years for group A and 2.06 years for group B $(P=\mathrm{NS})$. Delayed graft function (group $\mathrm{A}=22.7 \%$ vs group $\mathrm{B}=20.6 \%$ ) and acute rejections (group $\mathrm{A}=21.4 \%$ vs group $\mathrm{B}=18.4 \%)$ showed no significant differences $(P=$ NS). Graft function, sequentially assessed postransplantation by serum creatinine, was good and showed no difference $(P=$ NS) between groups at 1 month (group $A=1.86$ vs group $\mathrm{B}=1.85 \mathrm{mg} / \mathrm{dL}$ ), 3 months (group $\mathrm{A}=1.75$ vs group $\mathrm{B}=1.67$ $\mathrm{mg} / \mathrm{dL}$ ), 6 months (group $\mathrm{A}=1.58$ vs group $\mathrm{B}=1.67 \mathrm{mg} / \mathrm{dL}$ ), 1 year (group $\mathrm{A}=1.47 \mathrm{vs}$ group $\mathrm{B}=1.74 \mathrm{mg} / \mathrm{dL}$ ), and 2 years (group $\mathrm{A}=1.43$ vs group $\mathrm{B}=1.75 \mathrm{mg} / \mathrm{dL}$ ).

Actuarial cumulative graft survivals at 1 and 3 years were $88.73 \%$ and $82.23 \%$ for group A, and $87.34 \%$ and $84.11 \%$ for group B (log-rank NS). Causes of graft loss did not differ between the 2 groups. Actuarial cumulative patient survivals at 1 and 3 years were $96.34 \%$ and $93.00 \%$ for group A, and $97.30 \%$ and $93.69 \%$ for group B (log-rank NS). Causes of death were similar.

\section{DISCUSSION}

In the field of organ procurement and preservation there has been significant progress in understanding the mechanisms of cell damage induced by ischemia and in the development of new physiological and pharmacological approaches to the protection of tissues from ischemia. Hypothermia still remains the main method of organ preservation, and new solutions have attenuated the metabolic consequences of cold ischemia. Particular attention has been paid to the ischemia-reperfusion injuries and prevention of cell damage.

UW solution has been the "gold standard" for intraabdominal organs with good results in the preservation of liver and kidney, leading to excellent rates of immediate graft function and low short- and long-term serum creatinine levels. Celsior was first developed to meet the needs of intrathoracic organ preservation: low potassium, prevention of edema, prevention of free radical damage, and prevention of calcium overload with adequate buffer. ${ }^{3}$ Several reports, however, have also addressed its adequacy for intra-abdominal organs, potentially transforming this solution into a universal one, carrying all the advantages of flushing all the organs with the same product in multiorgan procurement procedures. $^{4,5}$

As we previously reported, in our center during the last years multiorgan procurements became the most common procedures, transforming a potentially universal flushing solution into a major benefit. ${ }^{6}$ This study compared 2 groups of preserved grafts with different solutions: UW and Celsior. Although there were some differences in the population characteristics (donor age, living donation, multiorgan harvests, and recipient comorbidities), we think both groups were roughly comparable. In accordance with other authors, we did not find any differences in the rates of immediate graft function, acute rejection, or graft function in the short- and long-term. ${ }^{2,7,8} \mathrm{Graft}$ and patient survivals were also similar, letting us conclude that UW and Celsior solutions have the same profile of efficacy in cold storage and kidney preservation. Celsior has the advantage of being an appropriate solution for intrathoracic and liver preservation, organs that we routinely harvest in our hospital.

\section{REFERENCES}

1. de Boer J, De Meester J, Smits JM, et al: Eurotransplant randomized multicenter kidney graft preservation study comparing HTK with UW and Euro-Collins. Transpl Int 12:447, 1999

2. Pedotti P, Cardillo M, Rigotti P, et al: A comparative prospective study of two available solutions for kidney and liver preservation. Transplantation 77:1540, 2004

3. Menasche P, Termignon JL, Pradier F, et al: Experimental evaluation of Celsior, a new heart preservation solution. Eur J Cardiothorac Surg 8:207, 1994

4. Baldan N, Toffano M, Cadrobbi R, et al: Kidney preservation in pigs using Celsior, a new organ preservation solution. Transplant Proc 29:3539, 1997

5. Cavallari G, Catena F, Santoni B, et al: Kidney preservation in pigs with University of Wisconsin and Celsior solution. Minerva Chir 57:295, 2002

6. Nunes P, Parada B, Pratas J, et al: Cadaveric donor factor variations during a 12 -year period: influence on kidney transplant outcomes. Transplant Proc 38:1867, 2006

7. Faenza A, Catena F, Nardo B, et al: Kidney preservation with University of Wisconsin and Celsior solution: a prospective multicenter randomized study. Transplantation 72:1274, 2001

8. Karam G: Safety of the use of Celsior in kidney-pancreas transplantation. Prog Urol 13:46, 2003 